Artigos

Volume 9 - 2019|n. 12

\title{
O Fundo Público e os Recursos Destinados à Educação: uma análise sobre dois municípios do estado do Paraná
}

\author{
Polyana Lunelli \\ Universidade Federal do Paraná (UFPR), Curitiba/PR - Brasil
}

\section{Resumo}

O presente artigo visa analisar a importância do fundo público na garantia da oferta da política pública de educação e a sua relação no processo de financiamento da política. As principais fontes de recursos da educação são provenientes da arrecadação de impostos dos entes federados - da União, dos estados e Distrito Federal e dos municípios e da contribuição social do salário-educação. Para tanto, serão analisados dois municípios situados no estado do Paraná: o município de Almirante Tamandaré e o município de Araucária, verificando como se efetiva o regime de colaboração na oferta da educação básica e os impactos que a receita resultante de impostos de ambos os municípios ocasiona na oferta do ensino público.

Palavras-chave: Fundo Público. Financiamento da Educação. Região Metropolitana de Curitiba.

\section{The Public Funds and the Resources aimed to Education: an analysis on two municipalities of the State of Paraná}

\begin{abstract}
This article aims to analyze the importance of public funds to guarantee the public education policy and its relevance in the process of financing of education. The main education's sources of assets are coming from of taxes of federated entities - the Union, the States and municipalities and from the social contribution of education salary. Therefore, two municipalities from the state of Paraná will be analyzed: Almirante Tamandaré and Araucária, verifying how the collaboration scheme in the offer of K-12 education works and the impact of tax revenue both of municipalities to the public education.
\end{abstract}

Keywords: Public Funds. Financing of Education. Curitiba Metropolitan Area. 
O Fundo Público e os Recursos Destinados à Educação

\section{Introdução}

Afinal, de onde vem os recursos destinados à educação pública e de quem é a responsabilidade pelo financiamento desse orçamento?

Após um processo histórico de avanços e retrocessos em suas Constituições, no que remete ao direto à educação, a Constituição da República Federativa do Brasil de 1988 representou um marco significativo para a educação brasileira: além de estabelecer diretrizes e normas, reconheceu a educação como um direito social e um direito público subjetivo. Estabeleceu, igualmente, as fontes de recursos e como seria efetivado o financiamento da Educação Básica e demais etapas de ensino. Como afirma Cury (2007, p. 833), "a existência desse liame entre Constituição, impostos e recursos vinculados".

O financiamento da educação é um processo complexo e suas fontes de recursos são variadas. As principais fontes desse custeio são provenientes da arrecadação de impostos dos entes federados - da União, dos estados e Distrito Federal e dos municípios, e da contribuição social do salário-educação. Os municípios brasileiros contam com as transferências de recursos provenientes do Fundo de Manutenção e Desenvolvimento da Educação Básica e Valorização dos Profissionais da Educação (FUNDEB), que se caracteriza como uma forma de redistribuição dos impostos.

Nesse contexto, o fundo público tem um papel fundamental na garantia dos direitos sociais e na oferta de uma série de serviços considerados essenciais à população, sendo responsável, sobretudo, pelo provimento da política pública da educação.

Como explicitam Salvador e Teixeira (2014, p. 21), "[...] o financiamento do orçamento não se limita a arrecadação de tributos (impostos, taxas, contribuições sociais e econômicas) [...], mas precisamente a entrada de recursos financeiros que aumentam a disponibilidade do fundo público". É esse fundo público, composto por recursos públicos, que será capaz de oferecer as condições materiais para a viabilização das políticas educacionais, bem como o "[...] atendimento das necessidades e demandas por bens e serviços educacionais" (CASTRO, 2010, p. 169).

Tendo isso em vista, o presente artigo busca analisar o papel do fundo público na garantia do provimento da política pública de educação e a sua relação no processo de financiamento de tal política. Para tanto, serão analisados dois municípios, situados no estado do Paraná: Almirante Tamandaré e Araucária, no intuito de verificar como se efetiva neles a distribuição das matrículas na oferta da educação básica e os reflexos que a receita resultante de impostos de ambos os municípios ocasiona na oferta do ensino público.

Para efetivação deste estudo, foram utilizados os dados da Sinopse Estatística da Educação Básica 2017, do Instituto Nacional de Estudos e Pesquisas Educacionais Anísio Teixeira (INEP), e do Sistema de Informações Sobre Orçamento Público em Educação (SIOPE), referentes ao ano de 2017.

\section{As Principais Fontes de Recursos e o Financiamento da Educação Básica}

A partir da Constituição Federal de 1988 (CF/1988) e das leis promulgadas posteriormente, a educação passou a ser efetivamente regulamentada, inclusive no Estatuto 
O Fundo Público e os Recursos Destinados à Educação

da Criança e do Adolescente - Lei ${ }^{\circ}$ 8.069/1990, na Lei de Diretrizes e Bases da Educação Nacional (LDB) - Lei n 9.394/1996, no Plano Nacional de Educação - Lei no 13.005/2014, com vigência entre 2014-2024, bem como nas resoluções do Conselho Nacional de Educação (CNE), entre outras legislações. Castro $(2010$, p. 171) ressalta que "[...] esse arcabouço jurídico assegura a todos os brasileiros as condições formais para o exercício do direito básico à educação [...], além de fixar a atual estrutura de responsabilidades e competências para a oferta de educação no Brasil”.

A disponibilidade e a alocação de recursos para o setor da educação precisam ser balizadas pelas normas referentes às fontes de financiamento, aos deveres do Estado para com a educação, à hierarquia de prioridades em relação aos níveis e modalidades de ensino e as especificidades dos mesmos e à distribuição de competências entre os níveis governamentais (FARENZENA, 2006, p. 82).

Tanto Castro (2010) quanto Farenzena (2006) ressaltam a importância das normativas acerca do financiamento da educação como instrumento capaz de assegurar os direitos dos cidadãos e os deveres do Estado no cumprimento da legislação, determinando a distribuição de responsabilidades e competências entre os entes federados.

$\mathrm{Na}$ Constituição Federal de 1988 e na LDB estão estabelecidas as fontes de financiamento da educação: (1) os impostos próprios da União, dos estados, do Distrito Federal e dos municípios, assim como a receita proveniente de transferências que tenham como origem o recolhimento de impostos; (2) a contribuição social do salárioeducação; (3) outras contribuições sociais; (4) receita de incentivos fiscais. Destas, a receita de impostos e o salário-educação são as principais fontes financiadoras da educação, uma vez que representam, em termos de volume de recursos e de regularidade, a receita que tem financiado a expansão e qualificação da educação escolar pública no país (FARENZENA, 2006, p. 82).

A política pública de educação, conforme apontamento acima, conta com algumas fontes de recursos e financiamentos, com destaque para duas delas, principais responsáveis pelo montante designado à educação escolar pública: os recursos provenientes das receitas de impostos dos governos federal, estadual e municipal e a contribuição social do SalárioEducação1.

Além de tratar da universalização do acesso e da permanência da criança e do adolescente no ensino obrigatório, a CF de 1988 trata da vinculação de recursos e determina um percentual mínimo do orçamento a ser destinado à educação pública a fim de garantir sua efetivação, conforme disposto na lei. O Artigo 212 da Carta Magna estabelece que:

A União aplicará, anualmente, nunca menos de dezoito, e os Estados, o Distrito Federal e os Municípios vinte e cinco por cento, no mínimo, da receita resultante de impostos, compreendida a proveniente de transferências, na manutenção e desenvolvimento do ensino (EC n 14/1996) (BRASIL, 1988).

1 De acordo com informações da página eletrônica do Fundo Nacional de Desenvolvimento da Educação (FNDE), "[...] o Salário-Educação é uma contribuição social destinada ao financiamento de programas, projetos e ações voltadas para a educação básica pública, conforme previsto no $\S 5^{\circ}$ do Art. 212 da Constituição Federal de 1988", o qual é assim expresso: "A educação básica pública terá como fonte adicional de financiamento a contribuição social do salário-educação, recolhida pelas empresas na forma da lei". Fontes: <www.fnde.gov.br>. Acesso em 11 jul. 2018 e Brasil (1988). 
Há, portanto, uma vinculação constitucional que prevê o percentual a ser investido na educação pública brasileira, sobretudo no ensino obrigatório. No período anterior à promulgação da $E C n^{\circ} 59 / 2009$, o ensino obrigatório estava restrito ao ensino fundamental, cuja faixa etária contemplada era de 6 a 14 anos. A Emenda Constitucional $n^{\circ} 59$, de 11 de novembro de 2009, estabelece alterações no Art. 208 da CF de 1988, de forma a prever a obrigatoriedade da educação básica dos quatro aos 17 anos de idade, contemplando, dessa forma, as etapas da educação infantil, do ensino fundamental e do ensino médio e elevando os anos de escolaridade formal de nove para 14 anos.

O dinheiro destinado à execução da política de educação vem das três esferas de governo: da União, dos estados e Distrito Federal e dos municípios, sob regime de colaboração.

A educação, o primeiro dos direitos sociais descritos no Art. $6^{\circ}$ da CF de 1988 , será efetivamente ofertada à sociedade por meio do fundo público. "Uma das principais maneiras da realização do fundo público é por meio da extração de recursos da sociedade na forma de impostos, contribuições e taxas, da mais valia socialmente produzida" (SALVADOR, 2017, p. 428).

O sistema tributário brasileiro é composto por três tributos: impostos, taxas e contribuições; destes, apenas os impostos têm vinculação constitucional obrigatória com a educação. As taxas e contribuições têm destinação específica, já que os impostos constituem um grande fundo de financiamento do conjunto das ações do poder público (GOUVEIA, 2013, p. 83).

A autora ressalta que, dentre os tributos que compõem o sistema tributário brasileiro, somente os impostos têm vinculação constitucional com a educação. As chamadas taxas e as contribuições arrecadadas não entram no montante de recursos destinados à educação pública. Em relação aos impostos pagos pelos contribuintes, destacam-se os impostos sobre a propriedade e renda (incidência direta) e sobre o consumo de bens e serviços (incidência indireta) (GOUVEIA, 2013). A CF de 1988 determina as competências quanto ao estabelecimento dos impostos federais, estaduais e municipais, conforme explicitado no quadro 1.

Quadro 1 - As competências dos entes federados quanto à instituição dos impostos no Brasil

\begin{tabular}{|c|c|c|}
\hline NORMATIVA & ESFERA GOVERNAMENTAL & IMPOSTOS \\
\hline ARTIGO 153 & UNIÃO & $\begin{array}{l}\rightarrow \text { Imposto sobre importação (II); } \\
\rightarrow \text { Imposto sobre exportação (IE); } \\
\rightarrow \text { Imposto sobre a renda de proventos de qualquer natureza } \\
(\text { IR); } \\
\rightarrow \text { Imposto sobre produtos industrializados (IPI); } \\
\rightarrow \text { Imposto sobre operações financeiras (IOF); } \\
\rightarrow \text { Imposto sobre propriedade territorial rural (ITR); } \\
\rightarrow \text { Imposto sobre grandes fortunas (IGF). }\end{array}$ \\
\hline ARTIGO 155 & $\begin{array}{c}\text { ESTADOS E DISTRITO } \\
\text { FEDERAL }\end{array}$ & $\begin{array}{l}\rightarrow \text { Imposto sobre transmissão causa mortis e doação (ITCMD); } \\
\rightarrow \text { Imposto sobre circulação de mercadorias e serviços (ICMS); } \\
\rightarrow \text { Imposto sobre propriedade de veículos automotores (IPVA); } \\
\rightarrow \text { Imposto sobre a renda retido na fonte - funcionários estaduais } \\
(\text { IRRF). }\end{array}$ \\
\hline ARTIGO 156 & MUNICÍPIOS & $\begin{array}{l}\rightarrow \text { Imposto sobre propriedade predial e territorial urbano (IPTU); } \\
\rightarrow \text { Imposto sobre transmissão de bens imóveis, transmissão inter } \\
\text { vivos (ITBI); } \\
\rightarrow \text { Imposto sobre serviço de qualquer natureza (ISSQN). }\end{array}$ \\
\hline
\end{tabular}

Fonte: Constituição Federal (BRASIL, 1988). 
Parte do montante destinado à educação é proveniente dos recursos públicos, sob a forma de impostos extraídos da população e da riqueza produzida pela sociedade. Como afirma Behring (2012; 2016 apud SALVADOR, 2017, p. 428), "[...] é parte do trabalho excedente que se transformou em lucro, juro ou renda da terra, sendo apropriado pelo Estado para o desempenho de múltiplas funções e de trabalho necessário". Uma parcela de recursos direcionada ao Estado, cujo objetivo é o desenvolvimento de ações, a oferta de políticas sociais e a manutenção do capitalismo, como ressalta Salvador (2012, p. 5): "[...] no capitalismo contemporâneo, o fundo público exerce uma função ativa nas políticas macroeconômicas, sendo essencial tanto na esfera da acumulação produtiva quanto no âmbito das políticas sociais".

O fundo público teria uma participação fundamental na garantia de políticas e serviços públicos capazes de assegurar os direitos de cidadania da população. É fundamental para a execução e efetividade dos serviços essenciais, como as políticas públicas de Educação e Seguridade Social - Saúde, Previdência Social e Assistência Social. Conforme explicita Cury (2007, p. 851), os direitos sociais são "[...] um investimento que possui um custo saído dos fundos públicos. Assim, faz-se necessário apontar as fontes para o preenchimento desses fundos".

\begin{abstract}
A estrutura de financiamento da educação é mista e complexa, com a maior parte dos recursos provenientes de fontes do aparato fiscal, o caso típico dos recursos da vinculação de impostos. A vinculação de recursos de impostos para a educação reserva de determinado percentual do valor arrecadado - é uma das medidas políticas mais importantes para garantir a disponibilidade de recursos para o cumprimento do vasto rol de responsabilidades no poder público nessa área (CASTRO, 2010, p. 172).
\end{abstract}

O direito, o acesso e a permanência à educação tiveram suas limitações e impasses até atingirem o patamar da CF de 1988, de educação pública de qualidade a todos os cidadãos, indistintamente. Cury (2008, p. 1190) trata dos grupos historicamente excluídos do processo educacional e da garantia dos demais direitos civis, políticos e sociais e apresenta "o universo dos não-cidadãos ou cidadãos imperfeitos" durante o século XIX: os negros, os libertos, os índios e as mulheres. Grupos que teriam, durante anos, a garantia de seus direitos limitada ou condicionada ao seu status social.

No Quadro 2, apresenta-se um levantamento acerca da trajetória da vinculação de recursos orçamentários definidos ao longo das constituições brasileiras, entre avanços e retrocessos no que remete ao âmbito do investimento educacional e à responsabilização das esferas de governo na garantia da aplicação dos recursos. 


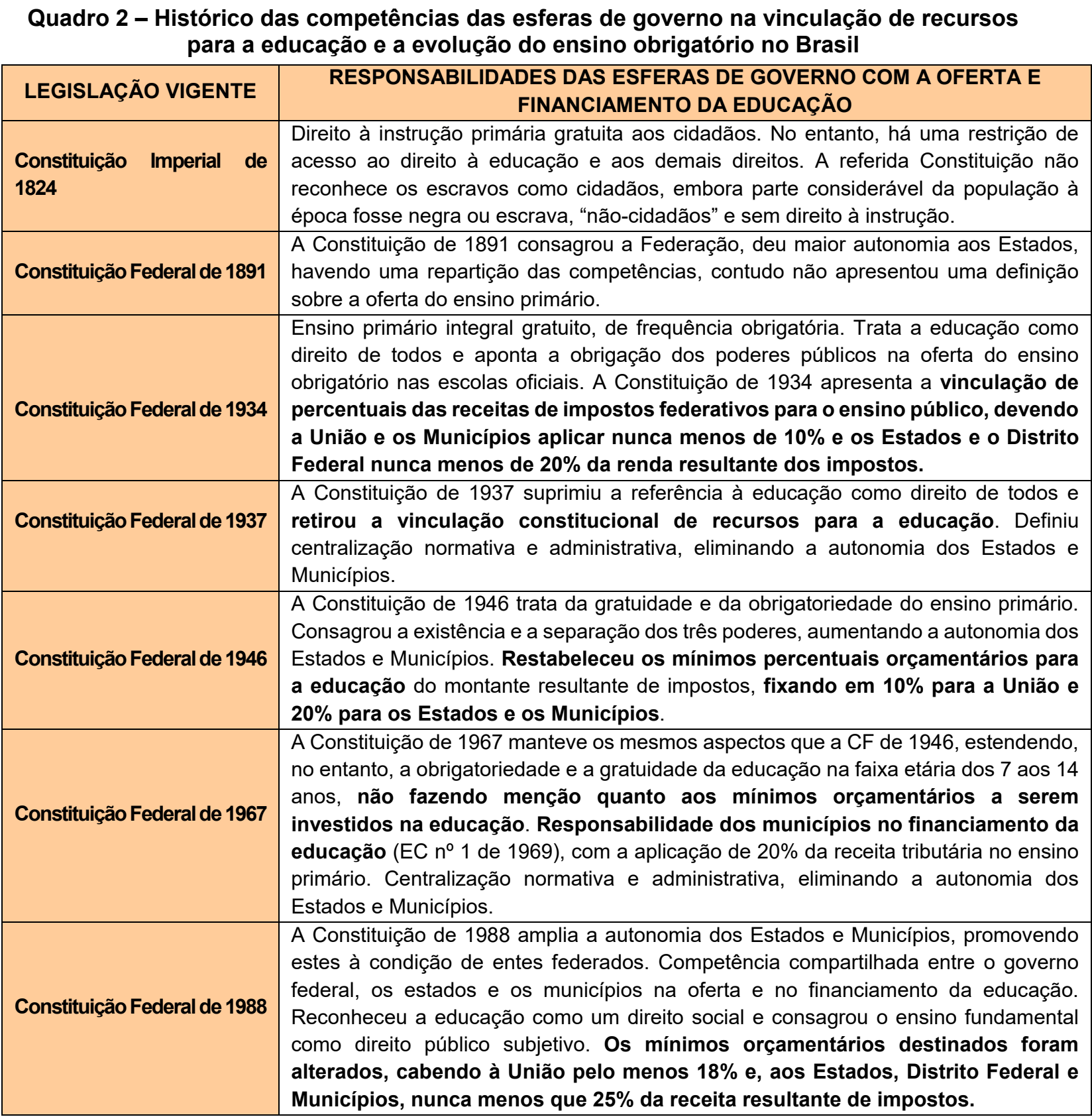

Fonte: $O$ quadro foi desenvolvido pela autora com base nas informações obtidas em Oliveira (1999); Farenzena e Marchand (2013) e Cury (2008).

Observa-se que foi na Constituição Federal de 1934 que surgiu a vinculação de recursos destinados à educação, contando com $10 \%$ da aplicação por parte da União e municípios e $20 \%$ por parte dos estados e Distrito Federal do montante arrecadado por meio dos impostos. A vinculação constitucional é omitida ou retirada das normativas vigentes em determinados períodos políticos, como Ditadura e Regime Militar.

A vinculação de recursos foi retirada da Constituição de 1937, no período da Ditadura do Estado Novo, sendo retomada somente na CF de 1946, com algumas adequações: a União aplicaria $10 \%$ e, os estados e os municípios, $20 \%$ da renda resultante dos impostos.

A Constituição de 1967 apresenta algumas características de seu período e contexto político, bem como de seu ambiente repressivo. "Deu-se o golpe de 1964, a partir do qual, 
durante 21 anos, o país viveu sob o governo autoritário militar" (OLIVEIRA, 1999, p. 24). De acordo com o autor, a centralização aumentou, reduzindo consideravelmente a autonomia dos estados e dos municípios.

A CF de 1988, por sua vez, altera novamente os mínimos orçamentários a serem investidos na educação pública e estabelece, em seu Art. 211, a organização dos sistemas de ensino, determinando a atuação e as competências das esferas governamentais: a União atuará, prioritariamente, na organização e financiamento das instituições de ensino públicas federais, além de cumprir papel supletivo na redistribuição de recursos entre os entes federados; os estados atuarão, sobretudo, na oferta do ensino fundamental e ensino médio e, os municípios, na educação infantil e ensino fundamental. Cury $(2010$, p. 151) ressalta que "[...] além das responsabilidades legislativas e normativas, há divisão das responsabilidades materiais e financeiras própria da vinculação de impostos para o financiamento da educação".

Há ainda uma repartição e divisão das responsabilidades quanto à oferta da educação básica entre os municípios e os estados. Tal divisão está além do financiamento de determinadas etapas de ensino ou da alocação de recursos para a educação, que envolve uma série de normativas e diretrizes que norteiam e conduzem o funcionamento das redes de ensino - sejam elas municipais ou estaduais.

Quirino (2018, p. 21) aponta que, além dos recursos advindos das vinculações constitucionais, da contribuição social do salário-educação, "[...] de convênios, projetos e programas vinculados ao Governo Federal, em especial por meio do Fundo Nacional de Desenvolvimento da Educação (FNDE) [...]; bem como outros recursos que possam vir a ser previstos em leis específicas", há os recursos disponibilizados pelo FUNDEB, que seria, segundo a autora, "[...] outra importante fonte de recursos para a educação nos municípios que ganham com o mesmo" (QUIRINO, 2018, p. 23).

\section{Os Fundos Contábeis FUNDEF, FUNDEB e a Política de Redistribuição de Recursos entre os Municípios}

Em 1996, no primeiro mandato do Presidente Fernando Henrique Cardoso (FHC), foi instituída a Emenda Constitucional $n^{\circ}$ 14/1996, regulamentada pela Lei $n^{\circ} 9.424 / 1996$, que cria o Fundo de Manutenção e Desenvolvimento do Ensino Fundamental e Valorização do Magistério (FUNDEF).

O FUNDEF cria uma subvinculação no orçamento da educação, destinado ao ensino fundamental. O mesmo será constituído por $15 \%$ do ICMS - imposto sobre circulação de mercadorias e sobre prestação de serviços, do FPE / FPM - fundo de participação dos Estados e Municípios e do IPI - imposto de produtos industrializados para exportação (OLIVEIRA, 1999, p. 30).

O FUNDEF opera no âmbito estadual e seria "abastecido" com os recursos provenientes das receitas de impostos e das transferências dos estados, do Distrito Federal e dos municípios. A complementação de recursos da União ocorreria em determinados estados, cujos municípios apresentassem maior desigualdade na arrecadação de seus impostos, especialmente se o valor por aluno não alcançasse o mínimo definido nacionalmente. Nesse debate sobre desigualdades, existe também o aporte de recursos da rede estadual, caso o valor por aluno não atinja o mínimo do estado, havendo redistribuição de recursos. 
Como 'mini-reformas-tributárias' (NEGRI, 1997 apud MARTINS, 2006), o Fundef e, agora, o Fundeb alteram a distribuição feita, por exemplo, pelos fundos de participação e pelas cotas do ICMS. Assim, recursos de alguns municípios podem financiar o ensino de outros ou do estado, e vice-versa (MARTINS, 2009, p. 130).

Um dos princípios do Fundo é a garantia de equidade entre os estados e os municípios brasileiros, por meio da redistribuição dos recursos destinados à educação, reduzindo as desigualdades intraestaduais e mantendo um valor mínimo de custo por aluno a ser atingido. Os recursos de alguns municípios, sobretudo os que contam com uma maior arrecadação de impostos, podem ser remanejados ou redistribuídos para municípios cuja arrecadação é menos volumosa. De acordo com Oliveira (1999, p. 32), "[...] a criação do fundo trouxe como consequência a possibilidade de o Município 'ganhar' ou 'perder' parte de seu próprio orçamento".

A Lei $n^{\circ} 9.424$ de 1996 estabelece que "[...] a distribuição dos recursos dar-se-á na proporção de alunos matriculados anualmente nas escolas cadastradas das respectivas redes de ensino, considerando apenas os matriculados no ensino fundamental" (Art. $2^{\circ}, \S 1^{\circ}$ ) (OLIVEIRA, 1999, p. 30). Portanto, o FUNDEF contribuiu para a universalização do ensino fundamental, garantindo maiores recursos aos municípios brasileiros mais pobres.

De acordo com Martins (2009, p. 194), "[...] muitos municípios passaram a contar com recursos maiores que os de seu Fundo de Participação do Município (FPM) e puderam pagar ao menos um salário mínimo a seus professores", realidade nas regiões mais carentes do País, nas quais a remuneração docente não atingia um salário mínimo mensal.

Com vigência até o ano de 2006, para, posteriormente, ser substituído pelo FUNDEB, o FUNDEF foi implantado e, de certa forma, imposto aos entes federados, em um momento político de ajuste fiscal, cujo objetivo era o crescimento econômico do País. O governo Fernando Henrique Cardoso (FHC) tratou de pôr em prática o Plano Diretor da Reforma do Aparelho do Estado (PDRAE), cuja linha, portanto, "[...] era de descentralização para os entes subnacionais, sobretudo, na direção da municipalização nos locais em que a rede ainda não fosse municipalizada [...]" (MARTINS, 2009, p. 124).

Dentre alguns apontamentos destacados acerca do FUNDEF, sobretudo no processo de avaliação do Fundo, houve convergência quanto aos elementos que deveriam permanecer na proposta do FUNDEB, de acordo com Martins (2009, p. 199): "[...] a natureza contábil do fundo; as contas únicas e específicas com repasses automáticos; a limitação do fundo ao âmbito de cada estado, sem redistribuição de recursos para além das fronteiras estaduais; entre outros". No entanto, dentre os aspectos negativos estão "[...] a limitação do Fundef ao ensino fundamental e a complementação insuficiente da União ao Fundef, o que comprometia a equidade entre os alunos de diferentes estados" (MARTINS, 2009, p. 199).

O período de vigência do FUNDEF foi de 10 anos, entre 1996 e 2006, sendo substituído pelo Fundo de Manutenção e Desenvolvimento da Educação Básica e de Valorização dos Profissionais da Educação (FUNDEB), por meio da Emenda Constitucional n 53/2006 e regulamentado pela Lei $n^{\circ} 11.494 / 2007$. Sobre a composição das fontes de receita do FUNDEB:

O fundo é composto, em cada território estadual, por $20 \%$ dos seguintes impostos e transferências: Impostos sobre Circulação de Mercadorias e Serviços (ICMS); Fundo de Participação dos Estados (FPE); Fundo de Participação dos Municípios (FPM); Imposto 
O Fundo Público e os Recursos Destinados à Educação

sobre Produtos Industrializados, proporcional às exportações (IPlexp); Desoneração de Exportações [...]; Imposto sobre a Propriedade de Veículos Automotores (IPVA); Imposto sobre Transmissão Causa Mortis e Doação de quaisquer bens ou direitos (ITCMD); Imposto sobre a Propriedade Territorial Rural (ITR). Além disso, integram os recursos do Fundo a complementação da União ( $10 \%$ do total dos fundos) para os Estados e Municípios que não alcançarem o valor médio ponderado por aluno definido nacionalmente para cada exercício (Emenda Constitucional n 53/06 e Lei $n^{\circ} 11.494 / 07$ ) (QUIRINO, 2018, p. 23).

De acordo com a página eletrônica do FNDE², o FUNDEB "[...] é um fundo especial, de natureza contábil e de âmbito estadual (um fundo por Estado e Distrito Federal, num total de vinte e sete fundos)". Tem um prazo de vigência até 2020 , com duração de 14 anos, a partir de sua promulgação - ocorrida em 2007, expandindo a cobertura do atendimento do ensino público para além do ensino fundamental, distinguindo-se do FUNDEF especialmente por esse aspecto. De acordo com Gouveia e Silva (2012, p. 310), "O FUNDEB [...] avança no sentido de ampliar a cobertura de seu atendimento, pois abarca também a educação infantil, o ensino médio e as modalidades da educação básica que não compunham o FUNDEF".

\section{A Arrecadação de Impostos e o Investimento em Educação: uma análise sobre dois municípios do estado do Paraná}

O estado do Paraná, localizado na Região Sul do Brasil, é dividido em 399 municípios e "[...] conta com um regime de colaboração no âmbito da educação construído por indução do governo do Estado já no início da década de 1990" (GOUVEIA; SILVA, 2012, p. 312). A responsabilidade pela oferta do ensino fundamental é compartilhada entre os municípios (com os anos iniciais $-1^{\circ}$ ao $5^{\circ}$ ano) e o estado (anos finais $-6^{\circ}$ ao $9^{\circ}$ ano).

Dentre os municípios que compõem o estado do Paraná, dois deles foram escolhidos para uma análise das receitas resultante de impostos, os reflexos e impactos dessa arrecadação sobre a possibilidade de investimento na educação dos respectivos municípios e se eles perdem ou ganham com o FUNDEB. O foco desse estudo foi, portanto, a análise dos municípios de Almirante Tamandaré e Araucária.

Ambos os municípios citados fazem parte do Primeiro Anel da Região Metropolitana de Curitiba (PARMC) (SUBIRÁ, 2013, p. 443), composto por aqueles que fazem limite com essa capital, somando-se a eles: Campina Grande do Sul, Campo Largo, Campo Magro, Colombo, Fazenda Rio Grande, Piraquara, Pinhais, Quatro Barras e São José dos Pinhais (IPARDES, 2018).

2 Disponível em: <www.fnde.gov.br/financiamento/fundeb>. Acesso em: 15 jul. 2018. 
Tabela 1 - Perfil dos Municípios analisados

\begin{tabular}{|c|c|c|c|c|}
\hline Município & $\begin{array}{c}\text { População Censo - } \\
\mathbf{2 0 1 0}\left(\mathbf{n}^{\mathbf{0}} \text { pessoas) }\right.\end{array}$ & $\begin{array}{c}\text { População estimada } \\
-\mathbf{2 0 1 7}\left(\mathbf{n}^{\mathbf{0}} \text { pessoas) }\right.\end{array}$ & $\begin{array}{c}\text { Densidade } \\
\text { demográfica } \mathbf{2 0 1 0} \\
\left(\mathbf{h a b} / \mathbf{k m}^{\mathbf{2}}\right)\end{array}$ & $\begin{array}{c}\text { IDHM* } \\
\mathbf{( 2 0 1 0 )}\end{array}$ \\
\hline $\begin{array}{c}\text { Almirante } \\
\text { Tamandaré }\end{array}$ & 103.204 & 115.364 & 529,95 & 0,699 \\
\hline Araucária & 119.123 & 137.452 & 253,86 & 0,740 \\
\hline
\end{tabular}

Fonte: Elaboração da autora com base em Instituto Brasileiro de Geografia e Estatística (IBGE, 2010; 2017); Instituto Paranaense de Desenvolvimento Econômico e Social (IPARDES, 2018). Nota: *Índice de Desenvolvimento Humano Municipal.

O município de Almirante Tamandaré, também conhecido como a "Cidade dos Minérios" com informações do Instituto Paranaense de Desenvolvimento Econômico e Social (IPARDES, 2018) e da página eletrônica da Prefeitura do Município, sua instalação ocorreu em meados de 1947 e sua fundação em 1956.

Em 2010, conforme os dados do Censo Demográfico do mesmo ano, o número de habitantes em Almirante Tamandaré era de 103.204 pessoas. A estimativa populacional em 2017, de acordo com o IBGE, é de 115.364 habitantes. O Município apresentou, em 2010, um Índice de Desenvolvimento Humano Municipal de 0,699 - permanecendo, segundo o IPARDES (2018), na posição $239^{\circ}$ no ranking do estado.

No que remete ao aspecto econômico, Almirante Tamandaré mantém uma forte atividade na área extrativista mineral, refletindo na geração de trabalho e renda e, sobretudo, na economia e arrecadação do município.

Atualmente, a economia e a produção do Município de Almirante Tamandaré estão relacionadas à produção agrícola [...] e também à produção de minérios [...] e minerais calcários, tendo grande influência na economia do município e empregando um grande número de pessoas (PEREIRA; PINTO, 2017, p. 23855).

No entanto, apesar de apresentar a indústria extrativista e a exploração do calcário como um aspecto positivo para o município - e não o deixa de ser - as autoras ressaltam que há "[...] vários impactos relacionados às questões ambientais, sociais, culturais e econômicas para a vida das comunidades" (PEREIRA; PINTO, 2017, p. 23856), o que pode ocasionar doenças respiratórias nos trabalhadores e moradores do entorno, acarretar a contaminação de nascentes e outros danos ambientais.

Em uma classificação dos municípios que compõem o Primeiro Anel da Região Metropolitana de Curitiba, de acordo com a receita per capita de 2010, Subirá (2013) categoriza os doze municípios - incluindo a capital de Curitiba - em três grupos: "Municípios Mais Ricos; Municípios Intermediários e Municípios Mais Pobres” (SUBIRÁ, 2013, p. 451). Almirante Tamandaré estaria situado entre os municípios mais pobres, enquanto Araucária, outro foco deste estudo, se encontra no grupo dos municípios mais ricos.

O município de Araucária foi fundado em 1890 e está localizado a cerca de 28 quilômetros da capital, Curitiba. O município, de acordo com dados do Censo Demográfico de 2010, apresentava um índice populacional de 119.123 habitantes e estimativa populacional

3 De acordo com a página eletrônica da Prefeitura de Almirante Tamandaré, "[...] a atividade extrativa mineradora sempre foi um dos grandes potenciais da cidade. Hoje, a cidade tem cerca de 20 indústrias de cal e calcário situadas próximo à Rodovia dos Minérios (PR-092)". Disponível em: <www.tamandare.pr.gov.br/nossacidade>. Acesso em: 15 jul. 2018. 
para 2017 de 137.452 habitantes, conforme o IBGE. Araucária apresentou, em 2010, Índice de Desenvolvimento Humano Municipal de 0,740 - permanecendo, de acordo com o IPARDES (2018), na classificação $54^{\circ}$ dentre os demais municípios do estado do Paraná.

De acordo com Gouveia e Souza (2005, p. 17), "[...] o município de Araucária apresenta grande crescimento populacional e é um dos principais responsáveis pela economia da região, pois concentra um grande polo petroquímico". Dentre os municípios da Região Metropolitana de Curitiba (RMC), é considerado um dos mais ricos, o que apresenta maior arrecadação de impostos e com maior PIB per capita. "A transformação da economia desse município teve início no ano de 1972, com a instalação milionária da Refinaria Presidente Getúlio Vargas (Repar), que estimulou a criação dos parques industriais e abrigou uma das refinarias da Petrobrás" (SUBIRÁ, 2013, p. 448).

Realizado esse panorama das condições socioeconômicas de Almirante Tamandaré e Araucária, com algumas especificidades quanto às principais atividades que movimentam a economia dos municípios, serão apresentadas, nas Tabelas 2 e 3, informações acerca da oferta da educação básica de ambos os municípios, no que remete ao número de estabelecimentos de ensino por dependência administrativa e etapa de ensino.

Tabela 2 - Estabelecimentos de ensino por dependência administrativa e etapa de ensino no município de Almirante Tamandaré, 2017

\begin{tabular}{|c|c|c|c|c|c|c|c|}
\hline \multirow{2}{*}{$\begin{array}{l}\text { Dependência } \\
\text { administrativa }\end{array}$} & \multicolumn{2}{|c|}{ Educação Infantil } & \multirow{2}{*}{$\begin{array}{c}\text { Ensino } \\
\text { Fundamental }\end{array}$} & \multirow{2}{*}{$\begin{array}{l}\text { Ensino } \\
\text { Médio }\end{array}$} & \multirow{2}{*}{$\begin{array}{l}\text { Ed. } \\
\text { Jovens e } \\
\text { Adultos }\end{array}$} & \multirow{2}{*}{$\begin{array}{c}\text { Educação } \\
\text { Especial }\end{array}$} & \multirow{2}{*}{ Total } \\
\hline & Creche & $\begin{array}{c}\text { Pré- } \\
\text { escola }\end{array}$ & & & & & \\
\hline Federal & - & - & - & - & - & - & - \\
\hline Estadual & - & - & 15 & 14 & 02 & - & 18 \\
\hline Municipal & 18 & 26 & 32 & - & 01 & - & 51 \\
\hline Particular & 04 & 04 & 05 & 01 & - & 01 & 07 \\
\hline Total & 22 & 30 & 52 & 15 & 03 & 01 & 76 \\
\hline
\end{tabular}

Fonte: Adaptada pela autora com base em Laboratório de Dados Educacionais do Núcleo de Políticas Educacionais da UFPR e IPARDES (2018). Tabela disponível em: <http://www.ipardes.gov.br>.

Nota: O mesmo estabelecimento pode ofertar mais de uma etapa de ensino. 
Tabela 3 - Estabelecimentos de ensino por dependência administrativa e etapa de ensino no município de Araucária, 2017

\begin{tabular}{|c|c|c|c|c|c|c|c|}
\hline \multirow{2}{*}{$\begin{array}{l}\text { Dependência } \\
\text { administrativa }\end{array}$} & \multicolumn{2}{|c|}{ Educação Infantil } & \multirow{2}{*}{$\begin{array}{c}\text { Ensino } \\
\text { Fundamental }\end{array}$} & \multirow{2}{*}{$\begin{array}{l}\text { Ensino } \\
\text { Médio }\end{array}$} & \multirow{2}{*}{$\begin{array}{l}\text { Ed. } \\
\text { Jovens e } \\
\text { Adultos }\end{array}$} & \multirow{2}{*}{$\begin{array}{c}\text { Educação } \\
\text { Especial }\end{array}$} & \multirow{2}{*}{ Tota } \\
\hline & Creche & $\begin{array}{l}\text { Pré- } \\
\text { escola }\end{array}$ & & & & & \\
\hline Federal & - & - & - & - & - & - & - \\
\hline Estadual & - & - & 15 & 17 & 01 & - & 20 \\
\hline Municipal & 35 & 41 & 35 & - & 06 & - & 73 \\
\hline Particular & 05 & 10 & 15 & 06 & 01 & 01 & 19 \\
\hline Total & 40 & 51 & 65 & 23 & 08 & 01 & 112 \\
\hline
\end{tabular}

Fonte: Adaptada pela autora com base em Laboratório de Dados Educacionais do Núcleo de Políticas Educacionais da UFPR e IPARDES (2018). Tabela disponível em: <http://www.ipardes.gov.br>.

Nota: O mesmo estabelecimento pode ofertar mais de uma etapa de ensino.

Almirante Tamandaré, no ano de 2017, contava com 76 estabelecimentos de ensino, divididos entre as dependências administrativas estadual, municipal e privada, não havendo instituição escolar da educação básica sob responsabilidade federal - ou da União. O município conta com 18 escolas estaduais, 51 instituições de ensino da rede municipal e 7 da rede particular, que atendem, no total, um contingente de 20.026 alunos matriculados.

O município de Araucária, em 2017, contava com 112 estabelecimentos de ensino, divididos entre as dependências administrativas estadual, municipal e privada. Assim como Almirante Tamandaré, Araucária não possui instituição escolar sob responsabilidade federal. O município possui 20 escolas estaduais, 73 instituições de ensino da rede municipal e 19 da rede privada, contemplando um total de 35.022 alunos matriculados.

Importante destacar a diferença entre o número de escolas privadas existentes nos dois municípios. Enquanto Almirante Tamandaré possui 7 instituições, Araucária apresenta quase três vezes mais, contando com 19 escolas particulares em seu território. Essa expansão do ensino privado e o crescimento das escolas particulares em determinados municípios estaria relacionado, segundo Camelo (2014), a dois fatores: ao crescimento populacional, nas cidades mais populosas, e, nos municípios mais ricos, pelo aumento de sua renda per capita.

Tanto os municípios mais populosos quanto os mais ricos experimentam, na última década, um crescimento mais expressivo da rede privada. Essa conclusão deve fazer sentido na medida em que esses são os municípios com maior demanda potencial (maior população) e com maiores possibilidades de acesso a serviços educacionais pagos (maior renda) (CAMELO, 2014, p. 10).

Apesar de o autor apresentar um estudo sobre a realidade de São Paulo, parece pertinente utilizá-lo para explicitar o que acontece nas demais regiões do País, sobretudo, no estado do Paraná. Araucária apresentaria, nesse caso, demanda de atendimento para as escolas particulares se estabelecerem nas dependências do município, garantindo a sua expansão. 
$\mathrm{Na}$ Tabela 4, serão apresentadas as receitas resultantes de impostos de ambos os municípios, o montante das receitas do FUNDEB e as despesas com Manutenção e Desenvolvimento do Ensino (MDE). Posteriormente, nas Tabelas 5 e 6, será apresentado o número de matrículas na Educação Básica por dependência administrativa e etapa de ensino.

Tabela 4 - Receitas resultantes de impostos - Demonstrativo das Receitas com Manutenção e Desenvolvimento do Ensino - MDE, Almirante Tamandaré e Araucária, 2017

\begin{tabular}{|c|c|c|}
\hline $\begin{array}{c}\text { Receita Resultante de } \\
\text { Impostos }\end{array}$ & $\begin{array}{c}\text { Almirante } \\
\text { Tamandaré }\end{array}$ & Araucária \\
\hline Receita de impostos & $18.014 .333,86$ & $114.587 .923,29$ \\
\hline $\begin{array}{c}\text { Receita de transferências } \\
\text { constitucionais e legais }\end{array}$ & $76.408 .509,00$ & $568.754 .458,04$ \\
\hline $\begin{array}{c}\text { Total da receita de impostos + } \\
\text { transferências }\end{array}$ & $94.422 .842,86$ & $683.342 .381,33$ \\
\hline Receitas do FUNDEB & $\begin{array}{c}\text { Almirante } \\
\text { Tamandaré }\end{array}$ & Araucária \\
\hline Receitas recebidas do FUNDEB & $36.056 .541,03$ & $89.311 .864,73$ \\
\hline Resultado líquido do FUNDEB & $21.070 .774,57$ & $-21.176 .323,73$ \\
\hline $\begin{array}{c}\text { Despesas com ações típicas } \\
\text { de MDE }\end{array}$ & $\begin{array}{c}\text { Almirante } \\
\text { Tamandaré }\end{array}$ & Araucária \\
\hline Educação Infantil & $9.269 .625,32$ & $24.716 .618,77$ \\
\hline Ensino Fundamental & $37.686 .344,19$ & $105.232 .354,51$ \\
\hline Total das despesas & $46.955 .969,51$ & $129.948 .973,28$ \\
\hline
\end{tabular}

Fonte: Dados extraídos do Sistema de Informações sobre Orçamento Público em Educação (SIOPE). Relatório Resumido da Execução Orçamentária. Período de Referência: 6º bimestre/2017.

Tabela 5 - Número de matrículas na Educação Básica por dependência administrativa e etapa de ensino, nos municípios de Almirante Tamandaré e Araucária, 2017*

\begin{tabular}{|c|c|c|c|c|c|c|c|c|c|c|c|c|c|c|c|c|c|c|c|c|c|c|c|c|c|}
\hline \multirow{3}{*}{ Municipio } & \multicolumn{10}{|c|}{ Educação Infantil } & \multicolumn{11}{|c|}{ Ensino Fundamental } & \multirow{2}{*}{\multicolumn{4}{|c|}{ Ensino Médio (E.M.) }} \\
\hline & \multicolumn{5}{|c|}{ Creche } & \multicolumn{5}{|c|}{ Pré-escola } & \multicolumn{5}{|c|}{ Anos Iniciais } & \multicolumn{6}{|c|}{ Anos Finais } & & & & \\
\hline & Total & Fed. & Est. & Mun. & Priv. & Total & Fed. & Est. & Mun. & Priv. & Total & Fed. & Est. & Mun. & Priv. & Total & Fed. & Est. & Mun. & Priv. & Total & Fed. & Est. & Mun. & Priv. \\
\hline $\begin{array}{l}\text { Almirante } \\
\text { Tamandaré }\end{array}$ & 838 & - & - & 749 & 89 & 1.718 & - & - & 1.554 & 164 & 6.966 & - & - & 6.429 & 537 & 5.645 & - & 5.134 & - & 511 & 3.121 & - & 3.101 & - & 20 \\
\hline Araucária & 1.960 & - & - & 1.798 & 162 & 3.711 & - & - & 3.371 & 340 & 11.945 & - & - & 10.551 & 1.394 & 9.284 & - & 5.041 & 3.248 & 995 & 5.946 & - & 5.280 & - & 666 \\
\hline
\end{tabular}

Fonte: Adaptada pela autora com base em Sinopse Estatística da Educação Básica 2017. Disponível em: $<$ http://portal.inep.gov.br/sinopses-estatisticas-da-educacao-basica>.

Notas: *O mesmo aluno pode ter mais de uma matrícula; não inclui matrículas de turmas de Atendimento Complementar e Atendimento Educacional Especializado (AEE).

Tabela 6 - Número de matrículas na Educação Básica por dependência administrativa e etapa de ensino, nos municípios de Almirante Tamandaré e Araucária, 2017* (continuação)

\begin{tabular}{|c|c|c|c|c|c|c|}
\hline \multirow{2}{*}{ Município } & \multicolumn{3}{|c|}{$\begin{array}{c}\text { Educação de Jovens e } \\
\text { Adultos (EJA) }\end{array}$} & \multicolumn{3}{c|}{ Educação Especial } \\
\cline { 2 - 7 } & Total & $\begin{array}{c}\text { Ensino } \\
\text { Fund. }\end{array}$ & $\begin{array}{c}\text { Ensino } \\
\text { Médio }\end{array}$ & Total & $\begin{array}{c}\text { Classe } \\
\text { Com. }\end{array}$ & $\begin{array}{c}\text { Classe } \\
\text { Exclus. }\end{array}$ \\
\hline $\begin{array}{c}\text { Almirante } \\
\text { Tamandaré }\end{array}$ & 1.639 & 1.009 & 630 & 631 & 500 & 131 \\
\hline Araucária & 1.632 & 1.063 & 569 & 916 & 806 & 110 \\
\hline
\end{tabular}

Fonte: INEP (2017).

A Tabela 4 apresenta as receitas resultantes de impostos dos municípios de Almirante Tamandaré e Araucária, relativos à MDE, conforme informações obtidas no SIOPE, referente 
ao $6^{\circ}$ bimestre de 2017. A intenção é demonstrar a capacidade de arrecadação dos dois municípios e o quanto essa diferença pode impactar no investimento em educação.

O município de Araucária é uma importante potência econômica na região, apresentando alta arrecadação de impostos, principalmente referente "[...] às transferências do ICMS decorrentes do Polo Petroquímico ali instalado" (GOUVEIA; SOUZA, 2005, p. 5). Por conta disso, apresentou uma perda de mais de 21 milhões em sua receita líquida do FUNDEB. Já o município de Almirante Tamandaré apresenta uma baixa arrecadação de impostos, o que implica em um ganho pelo FUNDEB de cerca de 21 milhões (receita líquida), possibilitando a ampliação de seu investimento em ações de MDE.

No entanto, apesar de Araucária contar com uma rede municipal mais ampla, no que remete à quantidade de estabelecimentos de ensino, e o número de alunos matriculados também ser superior, à Almirante Tamandaré, o investimento em ações de Manutenção e Desenvolvimento do Ensino é, conforme exposto na Tabela 4, mais elevado nas etapas da educação infantil e ensino fundamental, apresentando uma significativa diferença de investimento entre ambos os municípios.

Sobre a distribuição das matrículas nas etapas da Educação Básica e a responsabilização dos entes federados, é possível perceber que, conforme determinação da CF de 1988, em seu Art. 211, que trata sobre a organização dos sistemas de ensino e determina as competências das esferas governamentais, em ambos os municípios analisados não há qualquer participação da esfera federal ou estadual nas fases da educação infantil (creche e pré-escola), permanecendo essa etapa sob a responsabilidade dos municípios, com algumas incidências de matrículas na rede privada.

É importante destacar o número de crianças matriculadas em creche nos dois municípios. De acordo com um levantamento realizado por Ferreira (2017), a população com faixa etária para atendimento em creche, no ano de 2015, em Almirante Tamandaré, era de 7.359 crianças e, a de Araucária, era de 7.458 crianças. O número de matrículas para essa fase de ensino, em 2017, foi de 749 e 1.798, respectivamente - na rede pública.

Esse índice mostra a defasagem educacional na oferta da educação infantil, sobretudo na faixa etária de 0 a 3 anos. Os dois municípios ofertam um número de vagas relativamente baixo em relação à demanda apresentada, mas a situação de Almirante Tamandaré é ainda mais complexa. Araucária consegue contemplar um contingente maior de matrículas nessa fase - mantendo mais que o dobro de alunos matriculados na creche e na pré-escola.

No tocante ao ensino fundamental, em Almirante Tamandaré e Araucária, os anos iniciais são ofertados pela rede municipal. Destaca-se o número de matrículas na rede privada no município de Araucária: 1.394 alunos, cerca de 12\% das matrículas para essa fase do ensino fundamental.

A oferta dos anos finais, em Almirante Tamandaré, é de responsabilidade da rede estadual. O município possui $90,9 \%$ das matrículas sob competência do estado e, os outros $9 \%$, nas escolas particulares. Araucária apresenta um diferencial na divisão das competências na oferta dessa etapa de ensino, permanecendo $54,2 \%$ sob responsabilidade do Estado; $34,9 \%$ dos alunos matriculados na rede municipal e $10,7 \%$ de estudantes na rede privada de ensino. Ou seja, além de assumir a responsabilidade pela oferta dos anos iniciais, o município se compromete com um montante das matrículas dos anos finais do ensino fundamental. 
O Fundo Público e os Recursos Destinados à Educação

Sobre a distribuição das matrículas no ensino médio, o município de Almirante Tamandaré apresenta $99,3 \%$ de seus alunos frequentando a rede estadual de ensino e apenas $0,6 \%$ de matrículas na rede privada. No município de Araucária, o perfil é um pouco diferenciado, sendo $88,7 \%$ do contingente de matrículas na rede estadual e $11,2 \%$ nas escolas particulares. Novamente, Araucária se destaca pelo número de matrículas na rede privada de ensino.

$\mathrm{Na}$ Tabela 5, não foram especificadas as matrículas nas modalidades: Ensino Médio Normal/Magistério, Ensino Médio Integrado e Educação Profissional Técnica de Nível Médio e Educação Profissional - Formação Inicial Continuada (FIC). No entanto, faz-se necessário apontar que, na modalidade Educação Profissional Técnica de Nível Médio, o município de Almirante Tamandaré, no ano de 2017, contava com 244 alunos matriculados, enquanto Araucária apresentava um contingente de 1.173 matrículas, um montante significativamente superior em relação ao outro município analisado.

Outro destaque é voltado à modalidade Educação de Jovens e Adultos (EJA). De acordo com o IBGE (2017), Araucária conta com uma população estimada de aproximadamente 22 mil habitantes a mais que o município de Almirante Tamandaré, apresentando números de matrículas superiores na educação básica no decorrer deste estudo. No entanto, uma modalidade se destaca em Almirante Tamandaré por apresentar um índice ligeiramente mais elevado que Araucária: o número de alunos matriculados na EJA.

A LDB de 1996 descreve em seu Art. 37 que a EJA "será destinada àqueles que não tiveram acesso ou continuidade de estudos nos ensinos fundamental e médio na idade própria". De acordo com Reis (2014, p. 125), é necessário compreender a EJA "[...] não apenas como uma educação compensatória e emergencial, mas também como uma política educativa de fundamental importância para a superação de entraves sociais de uma ampla parcela de nossa população". Parcela esta que permaneceu fora da escola e, consequentemente, sem a possibilidade de uma maior inserção social (REIS, 2014).

Há uma relação entre educação de jovens e adultos e pobreza. O fato de Almirante Tamandaré apresentar um número elevado de matrículas nessa modalidade de ensino pode estar relacionado às condições de desigualdade e pobreza existentes no município, o que impossibilita uma maior escolaridade da população.

\section{Considerações Finais}

O fundo público tem um papel fundamental na garantia dos direitos sociais. Os recursos destinados à educação são os responsáveis pela garantia e efetivação do direito à educação e pelo cumprimento do que está disposto em lei, especialmente quanto aos mínimos percentuais a serem investidos e destinados a essa política pública.

O fato de um município contar com uma farta receita resultante de impostos, e uma maior receita per capita proveniente de sua arrecadação municipal, pode interferir na oferta e na qualidade da educação. No entanto, não era esse o objetivo deste trabalho. Foram levantadas algumas considerações acerca das instituições escolares (públicas e privadas), repartição das matrículas entre as dependências administrativas e algumas características que podem ser decorrentes da alta ou baixa arrecadação dos municípios analisados. 
Araucária é um município rico e conta com uma alta arrecadação de impostos, sobretudo de ICMS. Seu investimento em ações de MDE é igualmente alto. No entanto, na redistribuição realizada pelo FUNDEB, é um dos municípios que perde recursos próprios para o Fundo. Destacam-se, em Araucária, dois outros aspectos: o fato de contar com uma estrutura mais ampla de instituições privadas - desde a educação infantil até o ensino superior - e o fato de deter um número significativamente elevado de alunos matriculados na modalidade Educação Profissional Técnica de Nível Médio.

De acordo com um levantamento realizado por Subirá (2013), Araucária apresenta uma das melhores remunerações docentes entre os municípios que compõem o PARMC. Como explicita a autora (SUBIRÁ, 2013, p. 466), "[...] a melhor remuneração inicial dos professores destacou-se em Araucária". A autora ainda ressalta que os municípios mais pobres apresentam as piores remunerações docentes, os menores investimentos em MDE, apesar de receber os recursos provenientes dos fundos (SUBIRÁ, 2013).

A arrecadação de Almirante Tamandaré é baixa e seu investimento em ações de MDE é igualmente baixo - se comparadas ao montante gasto por Araucária. Por conta disso, é um município que pode contar com maior transferência de recursos do FUNDEB. Um aspecto relevante dentre os levantamentos realizados é o número de matrículas elevado na modalidade Educação de Jovens e Adultos no município, por razões já expostas durante a análise das Tabelas 5 e 6.

\section{Referências}

BRASIL. Constituição da República Federativa do Brasil. Diário Oficial da União, Brasília, 1988.

BRASIL. Lei n. 8.069, de 13 de julho de 1990. Dispõe sobre o Estatuto da Criança e do Adolescente e dá outras providências. Diário Oficial da União, Brasília, 1990. Disponível em: <http://www.planalto.gov.br/ccivil_03/leis//8069.htm>. Acesso em: 01 jun. 2018.

BRASIL. Lei n 9.394, de 20 de dezembro de 1996. Estabelece as diretrizes e bases da educação nacional. Diário Oficial da União, Brasília, 1996. Disponível em: <http://www.planalto.gov.br/ccivil_03/leis//9394.htm>. Acesso em: 01 jun. 2018.

BRASIL. Lei $n^{\circ}$ 11.494, de 20 de junho de 2007. Regulamenta o Fundo de Manutenção e Desenvolvimento da Educação Básica e de Valorização dos Profissionais da Educação FUNDEB, de que trata o art. 60 do Ato das Disposições Constitucionais Transitórias; altera a Lei no 10.195, de 14 de fevereiro de 2001; revoga dispositivos das Leis nos 9.424, de 24 de dezembro de 1996, 10.880, de 9 de junho de 2004, e 10.845, de 5 de março de 2004; e dá outras providências. Diário Oficial da União, Brasília, 2007. Disponível em: <http://www.planalto.gov.br/ccivil_03/_ato2007-2010/2007/lei//11494.htm>. Acesso em: 01 jun. 2018.

BRASIL. Lei n 13.005, de 25 de junho de 2014. Aprova o Plano Nacional de Educação - PNE e dá outras providências. Diário Oficial da União, Brasília, 2014. Disponível em: <http://www.planalto.gov.br/ccivil_03/_ato2011-2014/2014/lei//13005.htm>. Acesso em: 01 jun. 2018. 
O Fundo Público e os Recursos Destinados à Educação

CAMELO, Rafael. A Educação Privada em São Paulo: expansão e perspectivas. São Paulo: Fundação Seade, 2014.

CASTRO, Jorge Abrahão de. Financiamento da educação pública no Brasil: evolução dos gastos. In: OLIVEIRA, Romualdo Portela de; SANTANA, Wagner (Org.). Educação e Federalismo no Brasil: combater as desigualdades, garantir a diversidade. Brasília: UNESCO, 2010. p. 169-190.

CURY, Carlos Roberto Jamil. Estado e políticas de financiamento em educação. Educação \& Sociedade, Campinas, v. 28, n. 100, p. 831-855, out. 2007.

CURY, Carlos Roberto Jamil. Sistema Nacional de Educação: Desafio para uma educação igualitária e Federativa. Educação \& Sociedade, Campinas, v. 29, n. 105, p. 1187-1209, set./dez. 2008.

CURY, Carlos Roberto Jamil. A questão Federativa e a Educação Escolar. In: OLIVEIRA, Romualdo Portela de; SANTANA, Wagner (Org.). Educação e Federalismo no Brasil: combater as desigualdades, garantir a diversidade. Brasília: UNESCO, 2010. p. 149-168.

FARENZENA, Nalú. A política de financiamento da educação básica: rumos da legislação brasileira. Porto Alegre: Editora da UFRGS, 2006.

FARENZENA, Nalú; MARCHAND, Patrícia Souza. Relações intergovernamentais na Educação à luz do conceito de regulação. Cadernos de Pesquisa, São Paulo, v. 43, n. 150, p. 788-811, set./dez. 2013.

FERREIRA, Denize Cristina Kaminski. A efetivação do direito à Educação Infantil frente às políticas de Financiamento Educacional no Brasil. In: ENCONTRO ANUAL DA ASSOCIAÇÂO NACIONAL DE PESQUISA EM FINANCIAMENTO DA EDUCAÇÃO, 5., 2017, Curitiba. Anais... Universidade Federal do Paraná, Ano V, 2017.

GOUVEIA, Andréa Barbosa. O financiamento da educação no Brasil e o desafio da superação das desigualdades. In: SOUZA, Ângelo et al. Políticas Educacionais: conceitos e debates. Curitiba: Appris, 2013. p. 49-69.

GOUVEIA, Andréa Barbosa; SILVA, Isabelle Fiorelli. O gasto aluno-ano no Paraná (Brasil) e a situação de financiamento da educação nas regiões metropolitanas do Estado. Perspectiva, Florianópolis, v. 30, n. 1, p. 305-331, jan./abr. 2012.

GOUVEIA, Andréa Barbosa; SOUZA, Ângelo Ricardo de. O financiamento da educação em municípios da Região Metropolitana de Curitiba / PR / Brasil: Os desafios frente à expansão da oferta numa região em crescimento. Revista Electrónica de Geografia y Ciencias Sociales, Universidad de Barcelona, v. IX, n. 194, ago. 2005.

IPARDES - Instituto Paranaense de Desenvolvimento Econômico e Social. Caderno Estatístico: Município de Almirante Tamandaré. 2018. Disponível em: <http://www.ipardes.gov.br>. Acesso em: 15 jul. 2018.

MARTINS, Paulo de Sena. O financiamento da Educação Básica por meio de fundos contábeis: estratégia política para a equidade, a autonomia e o regime de colaboração entre os entes federados. 2009. Tese (Doutorado em Educação) - Faculdade de Educação, Universidade de Brasília. Brasília, 2009. 
O Fundo Público e os Recursos Destinados à Educação

OLIVEIRA, Cleiton de. A municipalização do ensino brasileiro. In: OLIVEIRA, Cleiton de et al. Municipalização do ensino no Brasil. Belo Horizonte: Autêntica, 1999.

QUIRINO, Simony Rafaeli. Transparência pública e financiamento da educação: uma análise a partir das leis orçamentárias. 2018. Tese (Doutorado em Educação) - Universidade Federal do Paraná, Curitiba, 2018.

REIS, Edna de Assis Ferreira. Desigualdade e educação: a ação da Educação de Jovens e Adultos (EJA) no município de Vila Velha - ES. 2014. Dissertação (Mestrado em Sociologia Política) - Universidade Vila Velha, Vila Velha, 2014.

SALVADOR, Evilasio. Fundo público e o financiamento das Políticas Sociais no Brasil. Serviço Social em Revista, Londrina, v. 14, n. 2, p. 04-22, jan./jun. 2012.

SALVADOR, Evilasio da Silva. O desmonte do financiamento da seguridade social em contexto de ajuste fiscal. Serviço Social \& Sociedade, São Paulo, n. 130, p. 426-446, set./dez. 2017.

SALVADOR, Evilasio; TEIXEIRA, Sandra Oliveira. Orçamento e políticas sociais: metodologia de análise na perspectiva crítica. Revista de Políticas Públicas, São Luís, v. 18, n. 1, p. 1532, jan./jun. 2014.

SUBIRÁ, Juliana Aparecida Alves. Remuneração inicial dos professores das redes municipais do Paraná no contexto municipal. Revista Brasileira de Estudos Pedagógicos (Estudos RBEP), Brasília, v. 94, n. 237, p. 439-473, maio/ago. 2013.

Polyana Lunelli é mestranda em Educação na Universidade Federal do Paraná - UFPR. Linha Políticas Educacionais. Pedagoga e Coordenadora de um Centro de Referência de Assistência Social no município de Curitiba/PR.

ORCID: http://orcid.org/0000-0003-1227-5207

E-mail: plunelli85@gmail.com 


\section{Editores do volume 9}

José Marcelino de Rezende Pinto - Universidade de São Paulo, São Paulo/SP, Brasil

Nalú Farenzena - Universidade Federal do Rio Grande do Sul, Porto Alegre/RS, Brasil

\section{Comitê Editorial}

José Marcelino de Rezende Pinto - Universidade de São Paulo, Brasil

Juca Gil - Universidade Federal do Rio Grande do Sul, Brasil

Theresa Adrião - Universidade Estadual de Campinas, Brasil Ângelo

Ricardo de Souza - Universidade Federal do Paraná, Brasil

Márcia Aparecida Jacomini - Universidade Federal de São Paulo, Brasil

\section{Conselho Editorial}

\section{Alejandro Morduchowicz}

Universidad Pedagógica, Provincia de Buenos Aires, Argentina

Fernanda Saforcada

Universidade de Buenos Aires, Argentina

Jacques Velloso

Universidade de Brasília, Brasil

João Monlevade

Senado Federal, Brasil

Jorge Abrahão de Castro

Instituto de Pesquisa Econômica Aplicada / IPEA, Brasil

Juca Gil

Universidade Federal do Rio Grande do Sul, Brasil

Lisete Regina Gomes Arelaro

Universidade de São Paulo, Brasil

Luis Carlos Sales

Universidade Federal do Piauí, Brasil

Luiz de Sousa Junior

Universidade Federal da Paraíba, Brasil

Luiz Fernandes Dourado

Universidade Federal de Goiás, Brasil

Magna França

Universidade Federal do Rio Grande do Norte, Brasil

\section{Maria Beatriz Luce}

Universidade Federal do Pampa, Brasil

Universidade Federal do Rio Grande do Sul, Brasil

Marcos Edgar Bassi

Universidade Federal de Santa Catarina, Brasil

\author{
Maria Dilnéia Espíndola Fernandes \\ Universidade Federal de Mato Grosso do Sul, Brasil \\ Nalú Farenzena \\ Universidade Federal do Rio Grande do Sul, Brasil \\ Nelson Cardoso do Amaral \\ Universidade Federal de Goiás, Brasil \\ Nicholas Davies \\ Universidade Federal Fluminense, Brasil \\ Rosana Evangelista Cruz \\ Universidade Federal do Piauí, Brasil \\ Rosana Gemaque \\ Universidade Federal do Pará, Brasil \\ Robert E. Verhine \\ Universidade Federal da Bahia, Brasil \\ Romualdo Portela de Oliveira \\ Universidade de São Paulo, Brasil \\ Theresa Adrião \\ Universidade Estadual de Campinas, Brasil \\ Tristan McCowan \\ University of London, Reino Unido \\ Vera Jacob \\ Universidade Federal do Pará, Brasil \\ Vera Peroni \\ Universidade Federal do Rio Grande do Sul, Brasil \\ Vitor Henrique Paro \\ Universidade de São Paulo, Brasil
}

\section{Equipe editorial}

Apoio ao Comitê Editorial: Patrícia Balthazar Garcia

Diagramação, Revisão de português e normalização: Edson Leonel de Oliveira

Revisão de inglês: Ananyr Porto Fajardo 